\title{
XXXIII. Observations on indirect chemical analysis
}

\section{Golding Bird F.L.S. F.G.S.}

To cite this article: Golding Bird F.L.S. F.G.S. (1838) XXXIII. Observations on indirect chemical analysis, Philosophical Magazine Series 3, 12:74, 229-232, DOI: $10.1080 / 14786443808649424$

To link to this article: http://dx.doi.org/10.1080/14786443808649424

册 Published online: 01 Jun 2009.

Submit your article to this journal 준

Џ Article views: 2

Q View related articles $₫$ 
substance, will not be attacked either by nitric acid of any degree of dilution, nor by a solution of blue vitriol. The voltaic association of one substance with the other is easily effected by connecting one end of an iron wire with the positive electrode of a pile, and by plunging for a few minutes the other end of the wire into a solution of nitrate of silver. ject.

I am just about to write a paper on this interesting sub-

Bâle, Dec. 31, 1837.

C. F. Schcendein.

XXXIII. Observations on indirect Chemical Analysis. By Golding Bird, F.L.S. F.G.S., Lecturer on Experimental Philosophy at Guy's Hospital, \&c.*

CASES constantly fall under the notice of the analytic chemist, in which, from the difficulty of separating one substance from another without a tedious operation, or from the absolute impossibility of effecting this separation in any thing like a perfect manner, the process of indirect analysis, as it has been termed, is particularly applicable. Thus, if whilst engaged in the analysis of the ash of an organic substance in which both potash and soda are contained, we require the quantitative amount of each base, almost every proposed process will to a certain extent fail. It is true that by the aid of hydro-fluosilicic acid, or the double chloride of platinum and sodium, we may obtain approximations to the truth, but even then the results obtained by these necessarily tedious processes are by no means so exact as those obtained by the aid of indirect analysis. A formula for the resolution of the last-mentioned problem (the quantitative estimation of potash and soda in mixtures of these bases) was proposed in Berzelius's work, Sur l'Analyse des Corps inorganiques, 1827, by the French translator; but this was certainly very tedious and not sufficiently comprehensive in its details. Poggendorff, in the third number of the invaluable "Handroürterbuch der reinen und angervandten Chemie von Liebig u. Poggendorff," has given two formulæ for the same purpose, which have the advantage of possessing considerable simplicity and of being applicable to the resolution of several analogous chemical problems. For the assistance of those who may not have an opportunity of consulting the original work, I have made the following abstract of the mode proposed by Poggendorff.

If the substances are bases which form with acids neutral salts of known composition, we take an exactly weighed

* Communicated by the Author. 


\section{$230 \mathrm{Mr} . \mathrm{G}$. Bird's Observations on indirect Chemical Analysis}

quantity of the mixture of the two bases and saturate it with an acid; and afterwards the same or an exactly equal quantity is to be saturated with a second acid. From the weight of the salts formed with the two acids, we get the weight of each base by calculation in the following manner.

\begin{tabular}{l|c|c|c}
\hline & $\begin{array}{c}\text { The base } \\
\text { A. }\end{array}$ & $\begin{array}{c}\text { The base } \\
\text { B. }\end{array}$ & $\begin{array}{c}\text { Known } \\
\text { weight of } \\
\text { the mixed } \\
\text { salts. }\end{array}$ \\
\hline $\left.\begin{array}{c}\text { Let the unknown quantity } \\
\text { by weight of ........... } \\
\begin{array}{c}\text { Let the unknown propor- } \\
\text { tion of salt formed by } \\
\text { the acid C .............. }\end{array}\end{array}\right\}=\mid \begin{array}{c} \\
\begin{array}{c}\text { Ditto by the acid D ...... } \\
\hline\end{array}=\end{array}=a^{\prime} x$, & $b^{\prime} y$ & $h^{\prime}$ \\
\hline
\end{tabular}

Then we have first,

$$
\begin{aligned}
& a x+b y=h \\
& a^{\prime} x+b^{\prime} y=h^{\prime}
\end{aligned}
$$

and consequently

$$
x=\frac{h b^{\prime}-h^{\prime} b}{a b^{\prime}-a^{\prime} b} \text { (3.) } \quad y=\frac{h^{\prime} a-h a^{\prime}}{a b^{\prime}-a^{\prime} b}
$$

Poggendorff then directs the respective values of $a, b, a^{\prime}, b^{\prime}$ to be deduced in the following manner.

If the atomic weights of

\begin{tabular}{|c|c|c|c|c|c|}
\hline $\mathbf{A}$ & B & A C & B C & $A D$ & B D \\
\hline $\mathbf{M}$ & $\mathrm{N}$ & $\mathbf{P}$ & $\mathbf{Q}$ & $\mathbf{P}^{\prime}$ & $\mathbf{Q}$ \\
\hline
\end{tabular}

The Bases.

The Salts.

it is clear that $a=\frac{\mathrm{P}}{m} \quad b=\frac{\mathrm{Q}}{n}$

$$
\boldsymbol{a}^{\prime}=\frac{\mathbf{P}^{\prime}}{m} \quad b^{\prime}=\frac{\mathbf{Q}^{\prime}}{n} ;
$$

that is, the unknown quantity of the salt $a x$, which the unknown quantity $x$ of the base $A$ forms with the acid $C$, must bear the same proportion to the quantity $x$, as the atomic weight of the A C bears to that of the base A. By means of the known atomic proportions are the quantities $a, b, a^{\prime}, b^{\prime}$ given, and with them by the formulæ (3.) and (4.) are the sought for proportions by weight, $x$ and $y$, of both bases found.

An example will render this clearer. Suppose that we have a mixture of potassa and soda and it is required to as- 
certain the exact proportions in which the two bases exist. We take two exactly equal portions of the mixture, and saturate one with sulphuric acid, the other with hydrochloric acid. Now, if the weight of the sulphates thus obtained is $2 \cdot 978656=h$.

Do. of hydrochlorates thus obtained is $2 \cdot 479338=h^{\prime}$. From their atomic weights we get the following proportions.

For sulphate of potassa.

For sulphate of soda.

$$
a=\frac{1091 \cdot 081}{589 \cdot 916}=1.84955 \quad b=\frac{892 \cdot 062}{390.897}=2.28209
$$

For hydrochlorate potass. For hydrochlorate soda.

$$
a^{\prime}=\frac{932.566}{589.916}=1.58085 \quad b^{\prime}=\frac{733.547}{390.897}=1.87657
$$

Then by the equations 3 . and 4 . we have

$$
\begin{aligned}
& \text { Potass ............ } x=0.5 \\
& \text { Soda ............ } y=0.9 .
\end{aligned}
$$

It is evident that mixed carbonates, acetates, \&c. of potass and soda may be used in the above process quite as easily as the pure bases, with which we rarely have to deal in analysis.

The above calculations become simpler, if, instead of using two portions of the mixed bases, we take but one and convert it into sulphates, if not already in that state; then knowing the weight of the mixed salts, we determine the quantity of sulphuric acid present by means of chloride of barium ; then the weight of the mixed sulphates minus the quantity of sulphuric acid gives us the weight of the mixed bases: let this weight be called $h^{\prime}$ in the equation (2.), and then consider $a^{\prime}$ and $b^{t}$ as equal to $1 ; h$ retaining its former value. The simplification of the formulæ thus proposed by Poggendorff will be rendered more obvious by copying them in this improved state; the only calculations required after determining the weights of the mixed sulphates and sulphuric acid being

$$
x=\frac{h-h^{\prime} b}{a-b} \quad y=\frac{h^{\prime} a-h}{a-b} .
$$

Even these calculations may be still further reduced if we substitute the following equation for finding the value of $y$; for that proposed by Poggendorff,

$$
h^{\prime}-x=y,
$$

and when we recollect that (in the case of potass and soda) $a$, and $b$, are constant quantities, we shall scarcely desire greater simplicity of calculation. As an example of this im- 
proved mode, I will take the following case, as it will serve to contrast the two processes.

We have a mixture of the sulphates of potass and soda whose united weights equal 53 ; on dissolving them in water and precipitating by chloride of barium, the quantity of sulphuric acid present was found to be 25 . Then $53-25=28$, the weight of the mixed bases. Then letting, as mentioned above,

the weight of sulphate $53=h ; a=1.84 .955$ \}

then of mixed bases $\left.28=h^{\prime} ; b=2 \cdot 28209\right\}$ as before;

$$
\begin{gathered}
(2 \cdot 28209 \times 28=63 \cdot 89852)=\left(h^{\prime} b\right) \\
(63 \cdot 89852-53=10 \cdot 89852)=\left(h^{\prime} b-h\right) \\
(2 \cdot 28209-1 \cdot 84955=0 \cdot 4.3254)=(a-b) \\
\left(\frac{h-h^{\prime} b}{a-b}\right)=\frac{10 \cdot 5985 \mathcal{L}}{\cdot 43254}=25 \cdot 19=x \text {, quantity of potass and } \\
\left(h^{\prime}-x\right)=28-25 \cdot 19=y \text {, quantity of soda. }
\end{gathered}
$$

This mode it is obvious is equally applicable to mixtures of barytes and strontia or lead, lime and magnesia, \&c., although it is evident that it will only give exact results when the atomic weights of the mixed bases differ considerably from each other; the greater this difference is, the more exact are the results. Still, however, it is much to be doubted whether the analytic chemist would not prefer the results of experiment to those of calculation, excepting in those cases where the mixed bases, as potass and soda, scarcely admit of quantitative estimation by direct experiment.

22, Wilmington Square, Jan. 3, 1838.

XXXIV. Further Observations on the ultimate Analysis of Organic Compounds. By RoBERT RIGG, M.R.I.**

IN my short paper on ultimate analysis which has already appeared in the Philosophical Magazine, p. 31, I described the method which I adopt in the examination of solid bodies only; I therefore now propose to submit to the analytical chemist my equally simple method of analysing liquids. Premising that the apparatus of tubes, \&c., together with the black oxide of copper, are such as have been heretofore described, I observe, in the first place, that the liquid to be analysed is accurately weighed in a small tube, whose length is from one to two inches, and whose diameter is such that it easily slicles within the analysing tube. Round a slender wire

- Communicated by the Author. 